\title{
Temperature and Species Measurements of Combustion Produced by a 9-Point Lean Direct Injector
}

Sarah A. Tedder and Yolanda R. Hicks

Glenn Research Center, Cleveland, Ohio

Randy J. Locke

ASRC Aerospace Corporation, Cleveland, Ohio 


\section{NASA STI Program . . . in Profile}

Since its founding, NASA has been dedicated to the advancement of aeronautics and space science. The NASA Scientific and Technical Information (STI) program plays a key part in helping NASA maintain this important role.

The NASA STI Program operates under the auspices of the Agency Chief Information Officer. It collects, organizes, provides for archiving, and disseminates NASA's STI. The NASA STI program provides access to the NASA Aeronautics and Space Database and its public interface, the NASA Technical Reports Server, thus providing one of the largest collections of aeronautical and space science STI in the world. Results are published in both non-NASA channels and by NASA in the NASA STI Report Series, which includes the following report types:

- TECHNICAL PUBLICATION. Reports of completed research or a major significant phase of research that present the results of NASA programs and include extensive data or theoretical analysis. Includes compilations of significant scientific and technical data and information deemed to be of continuing reference value. NASA counterpart of peer-reviewed formal professional papers but has less stringent limitations on manuscript length and extent of graphic presentations.

- TECHNICAL MEMORANDUM. Scientific and technical findings that are preliminary or of specialized interest, e.g., quick release reports, working papers, and bibliographies that contain minimal annotation. Does not contain extensive analysis.

- CONTRACTOR REPORT. Scientific and technical findings by NASA-sponsored contractors and grantees.
- CONFERENCE PUBLICATION. Collected papers from scientific and technical conferences, symposia, seminars, or other meetings sponsored or cosponsored by NASA.

- SPECIAL PUBLICATION. Scientific, technical, or historical information from NASA programs, projects, and missions, often concerned with subjects having substantial public interest.

- TECHNICAL TRANSLATION. Englishlanguage translations of foreign scientific and technical material pertinent to NASA's mission.

Specialized services also include creating custom thesauri, building customized databases, organizing and publishing research results.

For more information about the NASA STI program, see the following:

- Access the NASA STI program home page at http://www.sti.nasa.gov

- E-mail your question to help@sti.nasa.gov

- Fax your question to the NASA STI Information Desk at 443-757-5803

- Phone the NASA STI Information Desk at 443-757-5802

- Write to: STI Information Desk NASA Center for AeroSpace Information 7115 Standard Drive Hanover, MD 21076-1320 
NASA/TM-2013-217830

AIAA-2013-0562

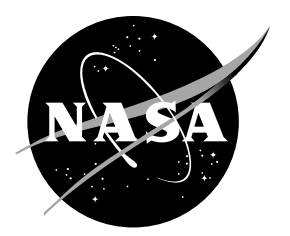

\section{Temperature and Species Measurements of Combustion Produced by a 9-Point Lean Direct Injector}

Sarah A. Tedder and Yolanda R. Hicks

Glenn Research Center, Cleveland, Ohio

Randy J. Locke

ASRC Aerospace Corporation, Cleveland, Ohio

Prepared for the

51st Aerospace Sciences Meeting

sponsored by the American Institute of Aeronautics and Astronautics

Grapevine, Texas, January 7-10, 2013

National Aeronautics and

Space Administration

Glenn Research Center

Cleveland, Ohio 44135 


\section{Acknowledgments}

This work was supported by the Aeronautical Sciences Project and the Subsonic Fixed Wing Project under the NASA Fundamental Aeronautics Program.

This work was sponsored by the Fundamental Aeronautics Program at the NASA Glenn Research Center.

Level of Review: This material has been technically reviewed by technical management.

Available from

NASA Center for Aerospace Information 7115 Standard Drive

Hanover, MD 21076-1320
National Technical Information Service 5301 Shawnee Road Alexandria, VA 22312 


\title{
Temperature and Species Measurements of Combustion Produced by a 9-Point Lean Direct Injector
}

\author{
Sarah A. Tedder and Yolanda R. Hicks \\ National Aeronautics and Space Administration \\ Glenn Research Center \\ Cleveland, Ohio 44135 \\ Randy J. Locke \\ ASRC Aerospace Corporation \\ Cleveland, Ohio 44135
}

\begin{abstract}
This paper presents measurements of temperature and relative species concentrations in the combustion flowfield of a 9-point swirl venturi lean direct injector fueled with JP-8. The temperature and relative species concentrations of the flame produced by the injector were measured using spontaneous Raman scattering (SRS). Results of measurements taken at four flame conditions are presented. The species concentrations reported are measured relative to nitrogen and include oxygen, carbon dioxide, and water.
\end{abstract}

\section{Nomenclature}

$\begin{array}{ll}\text { CARS } & \text { coherent anti-Stokes Raman spectroscopy } \\ \text { CFD } & \text { computational fluid dynamics } \\ \text { LDI } & \text { lean direct injection } \\ \mathrm{NO}_{\mathrm{x}} & \text { oxide of nitrogen } \\ \text { NASA } & \text { National Aeronautics and Space Administration } \\ \mathrm{OH} & \text { hydroxyl radical } \\ \mathrm{CH} & \text { carbon hydroxide radical } \\ \text { PIV } & \text { particle image velocimetry } \\ \text { PLIF } & \text { planar laser induced fluorescence } \\ \text { SRS } & \text { spontaneous Raman scattering }\end{array}$

\subsection{Introduction}

NASA is developing an advanced fuel injector design concept called lean direct injection (LDI) (Ref. 1) to reduce $\mathrm{NO}_{\mathrm{x}}$ emission produced by next generation of aircraft. $\mathrm{NO}_{\mathrm{x}}$ emission from aircraft contributes to the global warming effect. Lean direct injection has the potential to reduce $\mathrm{NO}_{\mathrm{x}}$ emissions while maintaining high combustion efficiency. To gain understanding of the flame produced by the LDI concept, a 9-point array of swirl venturi injector elements has been measured with various optical techniques (Refs. 2 to 6). All of these measurements combine to form a database of information on the LDI hardware. To add to this database, the same 9-point hardware has been measured with spontaneous Raman scattering (SRS). SRS can measure temperature and relative species concentrations in the high temperature, high pressure environment produced in the combustor with LDI. The temperature and species measurements made by SRS will help researchers studying the LDI concept to further understand the fuel air mixing characteristics of the combustion flow. The SRS measurements also can be used by CFD modelers to validate their models. 
The SRS temperature and species measurements were collected at four different operational conditions of the 9-point LDI hardware fueled with JP-8. The operational conditions vary in air inlet temperature, inlet pressure, flow rate, and fuel flow rate to the 9 LDI elements. These measurements complement previous measurements taken of the same hardware. Previous optical measurements taken include: OH PLIF (Ref. 3), Chemiluminsance of $\mathrm{OH}$ and $\mathrm{CH}$ (Refs. 2 and 3), High speed video (Ref. 4), PIV (Ref. 2), SRS, (Refs. 2 and 5) and CARS (Ref. 6). Previous SRS measurements taken in Reference 5, only reported on the feasibility of the application of the technique. The SRS measurements in Reference 2 reported temperatures at only one flame condition. The CARS measurements previously collected were taken at different flame conditions of the fuel injector than reported in this work (Ref. 6).

SRS is a spectroscopic laser diagnostic technique that can take one-dimensional and time resolved measurements in combustion flows (Refs. 7 and 8). Measurements were taken by traversing a laser beam and collection optics relative to the combustion flow. Measurements were collected every $5 \mathrm{~mm}$ in axial, horizontal, and veritical directions, generating a 3D volume of data. The data are presented as contour plots of 2D slices through the flow. The accuracy and precision of the temperature results are assessed using calibration data.

\subsection{Experimental Setup}

\section{$2.1 \quad$ Test Facility}

The LDI hardware was tested in a high temperature and high pressure flame tube combustor rig at NASA Glenn Research Center. The test section has optical access through three UV grade fused silica windows that are 38.1 by $50.8 \mathrm{~mm}$. The windows are on the top, left, and right side of the flame tube directly downstream of the fuel injector hardware. The swirl venturi 9-point LDI hardware is a 3 by 3 array of injectors. Figure 1 shows the LDI hardware tested with dimensions of 76.2 by $76.2 \mathrm{~mm}$. The injector elements are spaced on $25.4 \mathrm{~mm}$ (1 in.) centers. JP-8 fuel is injected through the center port of each element. Air is passed through the $60^{\circ}$ swirler vanes in the outer ring of each injector element.

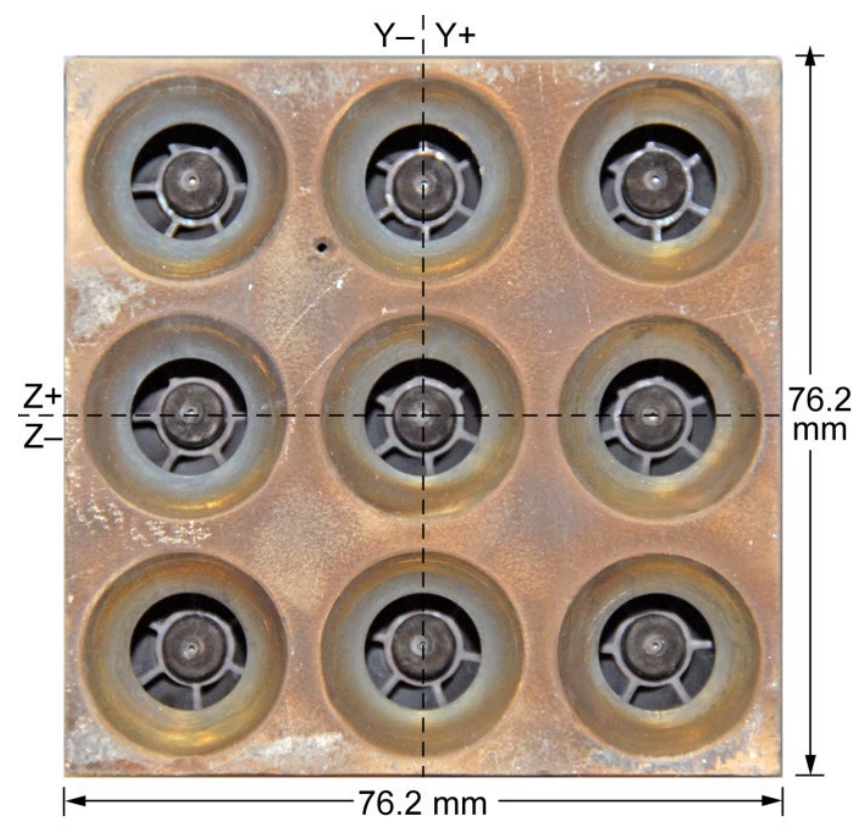

Figure 1.-Endview of the 9-point LDI test hardware. The hardware is 76.2 by $76.2 \mathrm{~mm}$. The LDI elements are spaced on $25.4 \mathrm{~mm}$ (1 in.) centers. 
TABLE 1.-OPERATING CONDITIONS OF THE 9-POINT LDI HARDWARE MEASURED WITH SRS

\begin{tabular}{|c|c|c|c|c|c|c|}
\hline \multicolumn{2}{|c|}{ Air } & \multicolumn{4}{c|}{ Fuel } \\
\hline $\begin{array}{c}\text { Inlet pressure, } \\
\text { psia }\end{array}$ & $\begin{array}{c}\text { Inlet temperature, } \\
\mathrm{K}\end{array}$ & $\begin{array}{c}\text { Flow rate, } \\
\mathrm{lbm} / \mathrm{s}\end{array}$ & $\begin{array}{c}\text { Center-inj } \\
\text { flow rate, } \\
\mathrm{lbm} / \mathrm{hr}\end{array}$ & $\begin{array}{c}\text { Outer 8-inj } \\
\text { flow rate, } \\
\text { lbm/hr }\end{array}$ & $\begin{array}{c}\text { Total, } \\
\phi\end{array}$ & $\begin{array}{c}\text { Estimated } \\
\mathrm{K}\end{array}$ \\
\hline 150 & 728 & 1.41 & 51 & 0 & 0.15 & 1090 \\
\hline 150 & 728 & 1.41 & 18 & 140 & 0.45 & 1749 \\
\hline 250 & 728 & 2.35 & 23 & 180 & 0.35 & 1545 \\
\hline 150 & 828 & 1.32 & 13 & 102 & 0.35 & 1626 \\
\hline
\end{tabular}

Table 1 shows the four flame conditions of the 9-point LDI at which SRS measurements were collected. These operating conditions vary in air inlet pressure, air inlet temperature, the fuel flow rate of the elements, and the overall equivalence ratio. For all but the first operating point shown in the table, the nine injectors were evenly fueled. For the first point, only the center injector was fueled.

\subsection{Optical Setup}

The optical setup up for the SRS system consists of three major parts: the excitation source, delivery system, and the collection optics. The excitation source is a Nd:YAG laser that outputs $\sim 45 \mathrm{~mJ}, 5 \mathrm{~ns}$ pulses at $532 \mathrm{~nm}$ with a repetition rate of $30 \mathrm{~Hz}$. This laser is housed in a room separate from the combustor. The laser beam is transmitted into the test facility using a delivery system made of a series of mirrors. The laser is passed into the test section through the top window and strikes the bottom surface of the test section. Directly before entering the test section, the laser is focused to increase the energy density at the measurement volume using a $300 \mathrm{~mm}$ focal length lens, as shown in Figure 2. The increase in energy density increases the signal-to-noise ratio of the Raman signal. However, the energy density at the laser focus is great enough to induce breakdown in air, thus destroying the gas composition at that location. Therefore, the collection optics are setup to collect Raman scattered light at a point $110 \mathrm{~mm}$ above the laser beam focus. This collection position allows the benefit of increased energy density while avoiding measurement volume breakdown and limiting the ablation of the bottom surface of the test section. The Raman scattered light is collected by a $60 \mathrm{~cm}$ collection lens. The light collected then is passed through a $532 \mathrm{~nm}$ notch filter and into a fiber optic with a vertical oriented linear array of fibers. The fiber optic transmits the collected signal to the $300 \mathrm{~mm}$ spectrometer. The light is dispersed with a 300 line/mm grating for the temperature measurements and with a $600 \mathrm{line} / \mathrm{mm}$ grating for species measurements. The gratings are optimized to reflect light at $500 \mathrm{~nm}$. The light is then collected on a 256 by 1024 pixel intensified CCD. The CCD pixel size combined with the 300 line/mm grating results in a $\sim 0.275 \mathrm{~nm} /$ pixel spectral resolution and combined with the 600 line $/ \mathrm{mm}$ grating in a $\sim 0.133 \mathrm{~nm} / \mathrm{pixel}$ spectral resolution. The intensifier of the CCD is optimized for visible wavelengths. The CCD is binned vertically into five rows, allowing simultaneous collection of 5 measurement locations in the vertical direction. This camera binning combined with the laser focus and collection optic qualities create a measurement volume cylindrical in shape, with the radius of $5 \mathrm{~mm}$ in the axial and horizontal directions and a height of $5.5 \mathrm{~mm}$ in the vertical direction.

Measurements were collected by traversing the laser beam and collection optics relative to the combustion flow. Measurements were collected over a range of locations in the axial, horizontal, and vertical directions, generating a $3 \mathrm{D}$ volume of data. The vertical direction is defined as the $\mathrm{z}$ direction, as drawn on the LDI hardware in Figure 1. Also shown in Figure 1, is the y direction, which is horizontal. Measurements were not taken over the full x plane but only at the locations shown in Figure 3(a). Figure 3(a) shows the center of the measurement locations with a "+" symbol and the measurement volume size with a red square. Note that some of the measurement volumes are overlapped in the $\mathrm{z}$ direction. The axial direction, $\mathrm{x}$, is defined as the direction of the flow, where $\mathrm{x}$ increases downstream. Measurements were taken in the $\mathrm{x}$ direction beginning $3.5 \mathrm{~mm}$ from the exit of the injector and ending $33.5 \mathrm{~mm}$ downstream. Figure 3(b) shows the measurement volume size and locations collected in the z plane. 


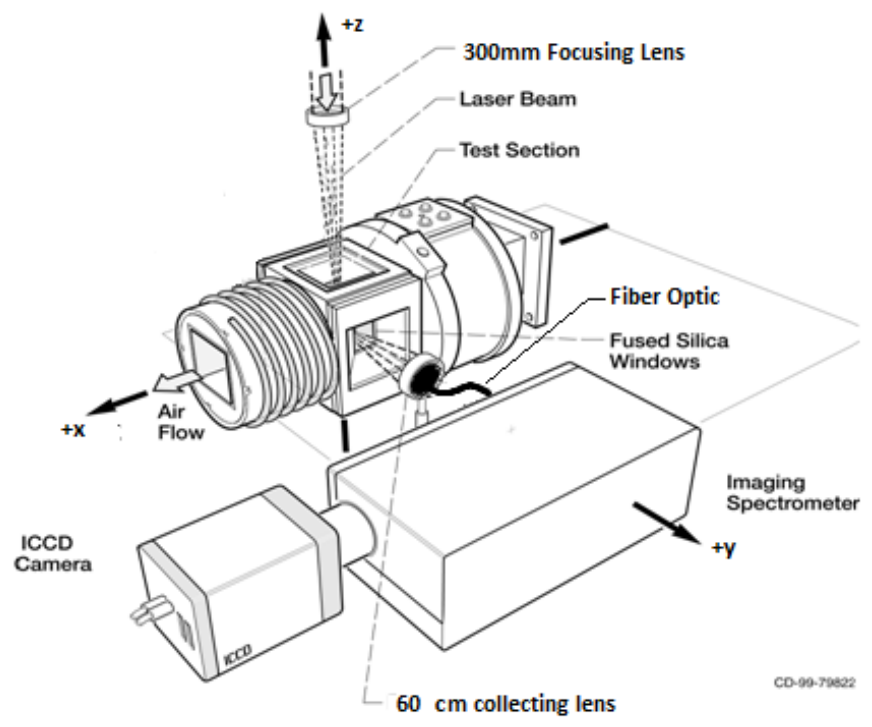

Figure 2.-Drawing of the optical setup at the test section.

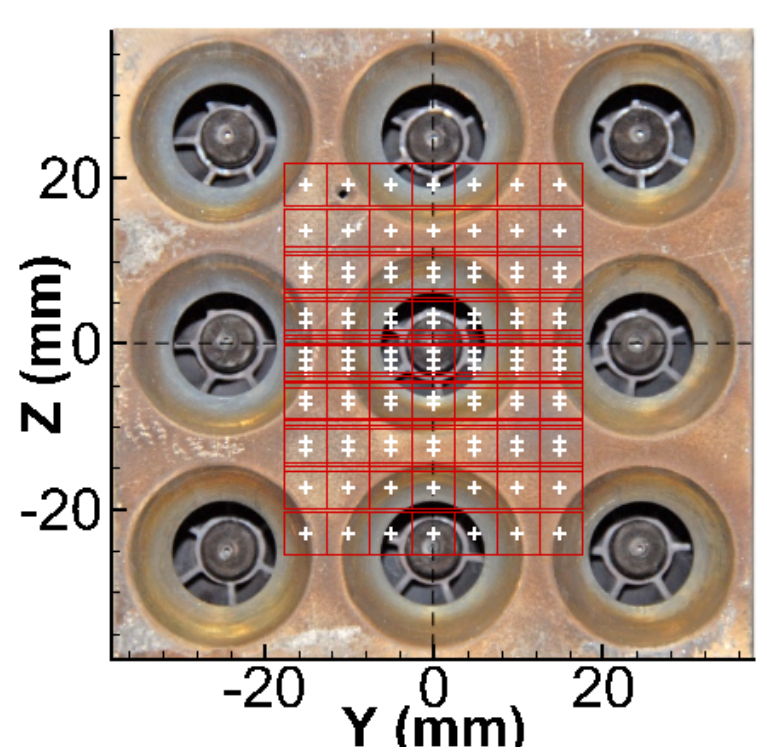

(a)

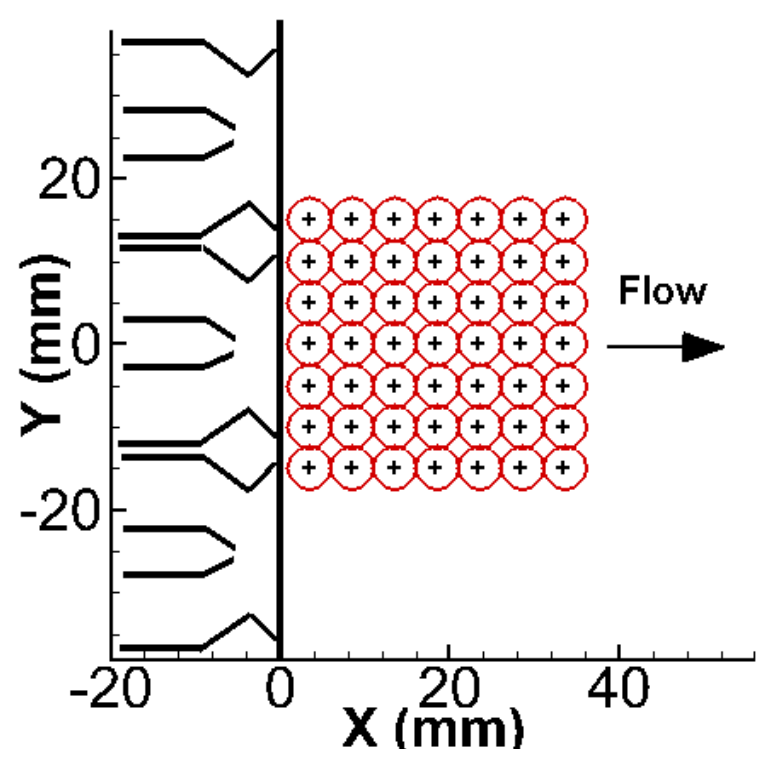

(b)

Figure 3.-Measurement locatıons and measurement volume sizes for (a) the x plane and (D) the $z$ plane. The center of the measurement locations relative to the 9-point LDI hardware collected are indicated with a "+" symbol. The size and shape of the measurement volumes are indicated by the red outlines.

\subsection{Calibration of Raman Spectra}

The Raman system must be calibrated for the effects of the optics used to collect the signal. Optics located in the path of the signal from the measurement volume to the collection optics also affect the signal. All these optics affect the efficiency of signal collection at each wavelength. In order to obtain accurate measurements of the temperature and species, the effects of these components must be calibrated. This calibration is performed by taking spectra in known environments. The spectra collected are used to determine coefficients. The coefficients are then used to determine species and temperature from spectra collected in unknown conditions. 


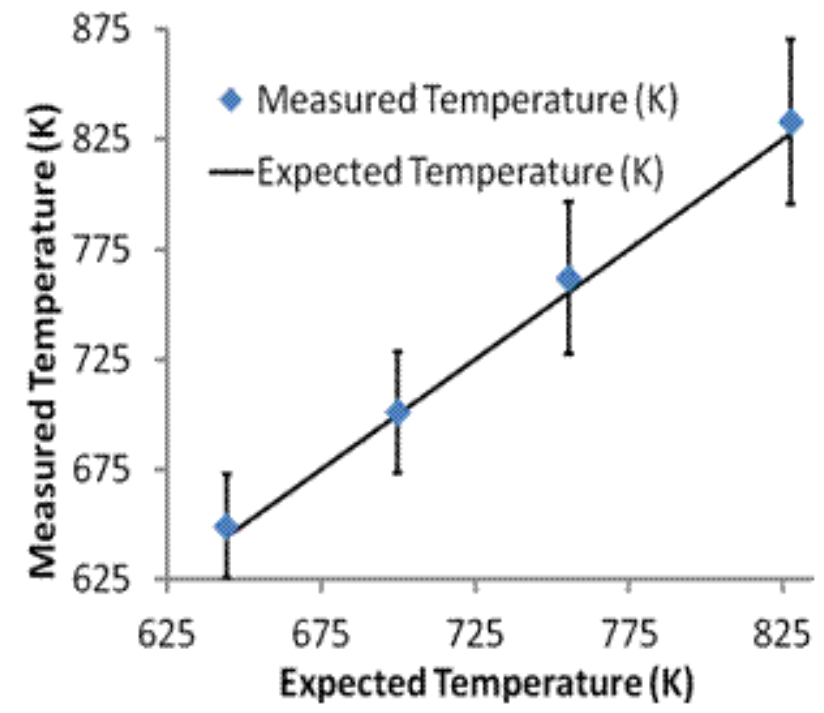

Figure 4.-Average measured temperature versus the expected temperature. Diamonds represent the average temperatures measured in the facility with hot air at known temperatures. The error bars indicate one standard deviation of the temperature measurements.

The temperature calibration measurements were performed in the facility with the hardware in place. Heated air was run through the facility at "known" temperatures (measured with a thermocouple). At each known temperature, measurements were collected along the three axes of the volume of the measurements, shown in Figure 3. The results of the temperature calibration are shown in Figure 4. The diamonds in Figure 4 represent the average of 70 collections from each calibration temperature. The error at each calibration temperature is on average $4 \mathrm{~K}$. The error bars in the Figure 4 represent one relative standard deviation. The average relative standard deviation of all the measured temperatures is 4 percent. Therefore, on average each collection of temperature will be accurate within 4 percent. Please note that the calibration temperature range does not include flame temperatures reached in this experiment and therefore is only an estimation of the accuracy at flame temperatures.

Because the laser strikes the bottom of the test section and the surface of the bottom of the test section varies in angle, height, and material varying amounts laser scatter is introduced into the spectra. This laser scatter varies with laser position and changes the calibration coefficient. The coefficients also vary across the vertical camera position (binned rows). This is because the intensity of collected light varies with laser energy. The laser energy is varying as the laser changes focus in the vertical direction.

To preserve the coefficient variance from changes in laser position and bin location, the calibration spectra collected along the axis of the volume of measurement locations (in Fig. 3 at $x=18.5 \mathrm{~mm}$, $\mathrm{y}=0 \mathrm{~mm}$, and $\mathrm{z}=-13,-7.45,-1.9,3.7$, and $9.25 \mathrm{~mm}$ ) were used to find the coefficients. Pairs of these lines of axis measurements of the coefficients (for example: $x$ and $y$ ) were fit to seven planes of the measurement locations. The seven planes fit are $\mathrm{x}=18.5 \mathrm{~mm}, \mathrm{y}=0 \mathrm{~mm}$, and $\mathrm{z}=-13,-7.45,-1.9$, 3.7, and 9.25. This allows coefficient variance to be estimated in the planes at which at least two rows of coefficients were measured. The temperature will only be reported in these planes. Preserving the spatial variation of the coefficient at each laser position and camera bin reduces the average percent error of the temperature from 5.5 to 4.2 percent. Figure 5 compares the percent error in the temperature in the $\mathrm{x}$ direction for a calibration with a uniform coefficient to a calibration coefficient with preserved variance in location. The figure indicates that the coefficient is affected by laser scatter the most at $\mathrm{x}$ locations near the exit of the injectors. 


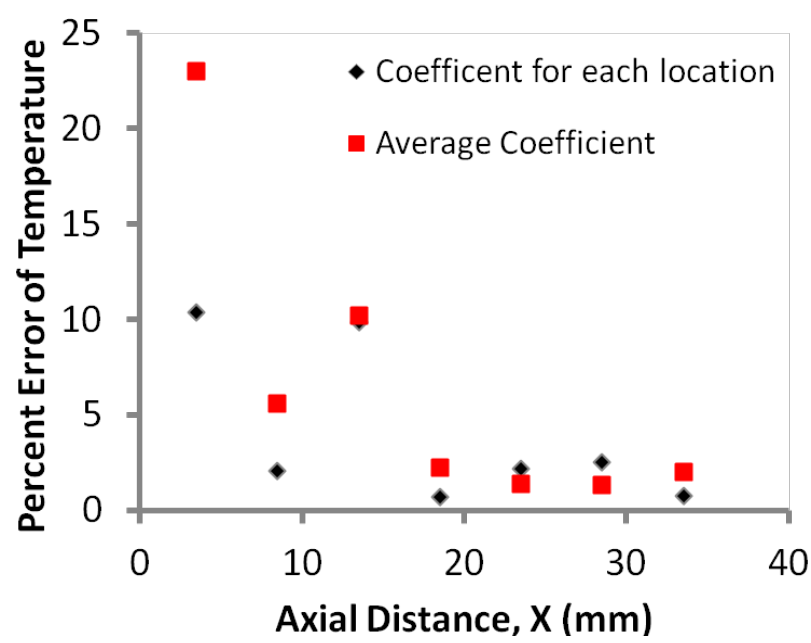

Figure 5.-Effect of preserving the change in coefficient with laser position. Plot of the percent error of measured temperature from the known temperature verses the axial distance from the nozzle exit of the injectors. The diamonds represent error found when the coefficients are averaged over all locations. The squares represent the error found with the location variance of the coefficients preserved.

The species calibrations were unable to be performed in situ. The calibration measurements were collected in a Raman cell containing gas mixtures of known compositions. These measurements were performed with all of the same exact optics as used in the facility except for the windows. The Raman cell windows were the same material as in the test section, UV grade fused silica, but were not the exact same windows; therefore the optical properties may be slightly different. Because the calibration was not performed in situ the spatial variance of the coefficients with laser position from the laser scatter were not measured. The spatial variance from the bin location (laser energy variance) was preserved. The coefficients were also found with only air and one gas mixture (7.2 percent methane, 11.2 percent carbon monoxide, 10.4 percent carbon dioxide, and the balance hydrogen); therefore, the accuracy and precision over a range of relative species concentrations to nitrogen could not be assessed.

\subsection{Data Analysis}

The Raman spectra collected are analyzed for temperature or relative species concentration. Each spectrum contains the light scattered from the molecules in the measurement volume. The wavelength of the inelastic scatter from each molecule is unique and corresponds to its characteristic vibrational and rotational energy levels. For this experiment, the relative intensity of the vibrational energy level spectral peaks is used to determine the temperature and the species concentration relative to nitrogen. The ratio of the area under the nitrogen anti-Stokes peak to the nitrogen stokes peak is used to determine the temperature. The ratios of the area under nitrogen Stokes peak to the Stokes peak of the other species (water, oxygen, and carbon dioxide) are used to determine the relative species concentration.

In order to determine the ratio of the spectral peaks accurately, background light contributed from the flame luminosity and the laser must be removed. The background light is collected at test condition and laser position with no laser present. This background is then subtracted from each spectrum at the corresponding location and test condition before the area under the curve of the spectral peaks is summed. Further background is removed by fitting a line to the intensity of $8 \mathrm{~nm}$ of surrounding wavelengths of the peak. Only the signal above this line was included in the summed intensity for each peak. Then the ratio of the summed intensity of the appropriate spectral peaks is found. Finally, the ratios are converted into temperature and species measurements using the coefficients determined with the calibration measurements. 


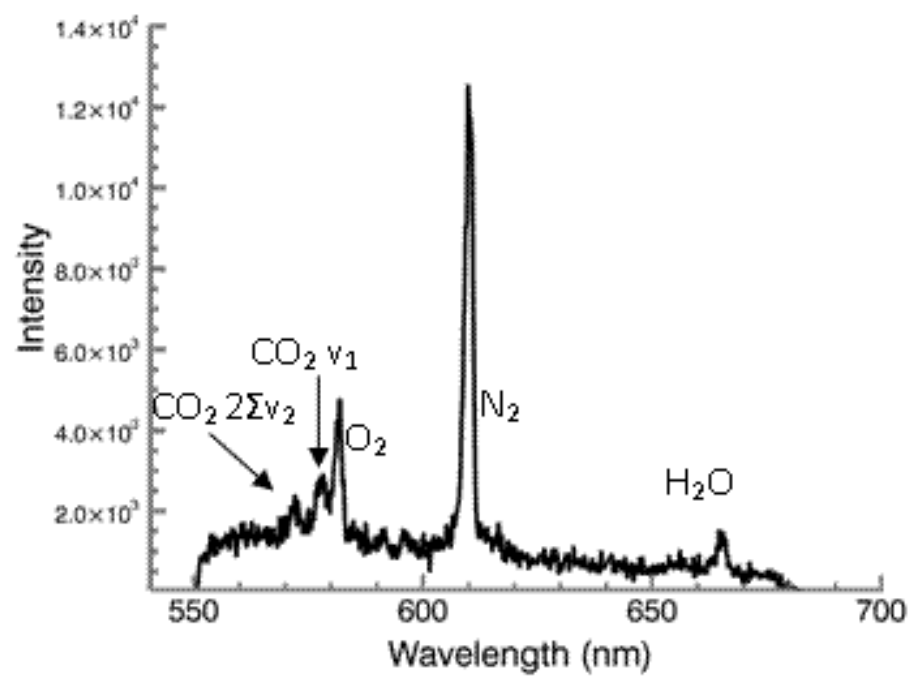

Figure 6.-A sample Raman spectrum. Plot of intensity verses wavelength of Raman spectral peaks of carbon dioxide, oxygen, nitrogen, and water.

Some species spectral peaks have overlapping wavelengths. For this experiment the spectral peaks carbon dioxide $\mathbf{v}_{1}$ and oxygen are overlapped, as seen in Figure 6. Therefore a carbon dioxide peak, $2 \Sigma \mathbf{v}_{2}$, which does not overlap with the oxygen peak, was used to find the relative concentration of carbon dioxide. There was not a similar option for oxygen. To find the oxygen concentration, the wavelength with the minimum intensity between the oxygen and the carbon dioxide $\mathrm{v}_{1}$ peak was chosen as the low end of the oxygen spectral peak wavelength range. Therefore, the oxygen reported in the results may be inaccurate because the summed intensity of the spectral peak contains varying unknown amounts of intensity contributed from the carbon dioxide spectral peak and may not contain all of the oxygen signal.

The spectra vary in signal-to-noise. Spectra having Stokes nitrogen peaks with signal-to-noise ratio less than 2 were rejected. The nitrogen Stokes peak was chosen as a standard because it is the largest peak and is present in every spectrum. The signal-to-noise is estimated by dividing the average intensity of the spectral peak by the standard deviation of the noise. The standard deviation of the noise is computed using the intensity from $4 \mathrm{~nm}$ of wavelength from each side of the spectral peak at wavelengths where no light is contributed from Raman scattering. Both accumulated (300, 5 ns exposures on-chip summed) and single shot spectra were collected. After analysis, all the single shot spectra were determined to have inadequate signal-to-noise to produce accurate measurements. Therefore only accumulated spectra are presented.

To allow easy interpretation of the results with the eye, the data are presented as 2D contour plots. These contours are found by a creating a mesh by triangulating a plane of data as shown in Figure 7. Figure 7 compares a scatter plot to the triangulated mesh of a z-plane of data. The scatter plot presents the temperatures in the shape and size of the measurement volume. The triangulated mesh shows the location of the measurements with black squares. The black lines are the mesh created by the triangulation. Note that the data point at $\mathrm{x}=18.5 \mathrm{~mm}$ and $\mathrm{y}=5 \mathrm{~mm}$ is missing. The data at this location were removed because of inadequate signal-to-noise. The triangulation of surrounding measurements allows an estimate of temperature in the unmeasured location using the surrounding measured temperatures. Missing data points occur most frequently at upstream locations. 

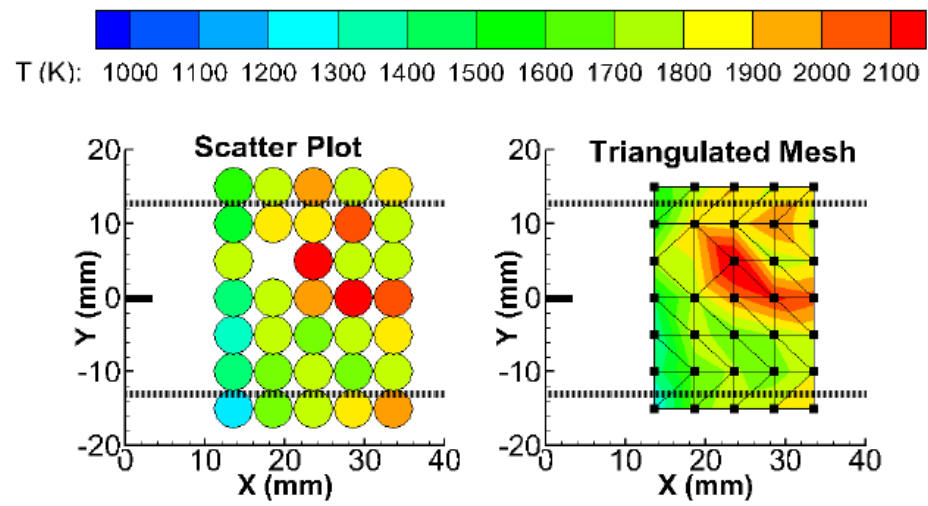

Figure 7.-Scatter Plot Compared to Triangulated Mesh. A plane of temperature data collected at the test condition, 150 psia and $728 \mathrm{~K}, \phi=0.45$, presented as a scatter plot and a triangulated mesh. The scatter plot shows the temperatures at the location and at the size of the measurement volume.

\subsection{Results and Discussion}

This section presents results of the SRS data collected at the operating conditions in Table 1. All results are presented as contour plots generated from planes of point measurements. The contour plots have missing information in locations where the signal-to-noise ratio of the nitrogen Stokes spectral peak did not exceed 2 . The location $(0,0,0)$ is the location within the exit plane, at the center of the center injector element. This is indicated as a thick small solid black line in plots of $\mathrm{y}$ and $\mathrm{z}$ planes and a cross hair in x planes. In figures presenting $y$ and $\mathrm{z}$ planes of data the dotted lines at $\mathrm{y}= \pm 12.7 \mathrm{~mm}$ indicate the half way point between two LDI elements (flat region in between the LDI elements in Fig. 1). The dotted circles in figures of $x$ planes of data represent the outside ring of the dome of the LDI elements (transition from angled to flat seen in Figure 1 between elements). In the y and $\mathrm{z}$ planes of data the flow proceeds from left to right in the axial direction, $\mathrm{x}$ (see Fig. 3(b)). The y planes show a side view of the combustion flow field at the center of the flow field in the $y$ direction $(y=0)$. The $x$ planes show a cross section of the flow field perpendicular to the direction of flow (see Fig. 3(a)). The $\mathrm{z}$ planes of data are a top view of the combustion flow field at five $\mathrm{z}$ locations (corresponding to the five $\mathrm{z}$ locations of the camera bins).

\subsection{Temperature}

To check whether the temperature measurements are reasonable, the spatial average of the measured temperatures at each condition is compared with the estimated flame temperatures in Table 2 . The average measured temperatures match well with the estimated flame temperature, except for the center injector only condition. This is because the estimated adiabatic flame temperature is calculated based on the overall equivalence ratio, whereas the Raman measurements are spatially resolved and are focused downstream of the center injector, as shown in Figure 3. Because of the Raman measurement location, the local equivalence ratio of 1.32 would be a more appropriate value to use to calculate the estimated flame temperature. This explains the high spatially averaged temperature for the center injector only condition. Temperature results for all four flame conditions at $\mathrm{y}=0 \mathrm{~mm}$ are shown in Figure 8. Note that at the 150 psia, $728 \mathrm{~K}$, center injector only condition and at the $150 \mathrm{psia}, 828 \mathrm{~K}, \phi=0.35$ condition measurements were not collected at all the locations shown in Figure 3. All temperatures measured exceed the inlet temperatures of 728 and $828 \mathrm{~K}$. The results show that the temperature increases as the flow progresses downstream at all flame conditions. The hottest conditions are measured at flame condition, $150 \mathrm{psi}, 728 \mathrm{~K}, \phi=0.45$, matching the highest estimated flame temperature in Table 2 . The highest temperatures for the center injector only flame condition (150 psi, $728 \mathrm{~K}, \phi=0.15)$ are similar to the $150 \mathrm{psi}, 728 \mathrm{~K}, \phi=0.45$ condition but are located only in the region directly downstream of the center 
injector. The next hottest flame temperature is predicted to be at the $150 \mathrm{psi}, 828 \mathrm{~K}, \phi=0.35$ condition and is matched by the measurements in Figure 8 . The coolest condition with all injectors in use is 250 psia, $728 \mathrm{~K}, \phi=0.35$ shown in Figure 8 to have the lowest temperatures.

Figure 9 shows the $x$ planes at the three flame conditions that fuel all the injector elements. The planes show a cross section at $\mathrm{x}=18.5 \mathrm{~mm}$, perpendicular to the flow. The temperature trends match those shown in Figure 8, with the hottest temperatures at flame condition, 150 psi, $728 \mathrm{~K}, \phi=0.45$.

TABLE 2.-ESTIMATED FLAME TEMPERATURE COMPARED TO THE SPATIAL AVERAGE OF THE MEASURED TEMPERATURE

\begin{tabular}{|c|c|c|c|c|}
\hline \multicolumn{2}{|c|}{ Air } & \multicolumn{3}{|c|}{ Fuel } \\
\hline $\begin{array}{c}\text { Inlet pressure, } \\
\text { psia }\end{array}$ & $\begin{array}{c}\text { Inlet temperature, } \\
\mathrm{K}\end{array}$ & $\begin{array}{c}\text { Total, } \\
\phi\end{array}$ & $\begin{array}{c}\text { Estimated } \mathrm{T}_{\text {flame, }}, \\
\mathrm{K}\end{array}$ & $\begin{array}{c}\text { Average measured } \mathrm{T}_{\text {flame}}, \\
\mathrm{K}\end{array}$ \\
\hline 150 & 728 & 0.15 & 1090 & 1663 \\
\hline 150 & 728 & 0.45 & 1749 & 1773 \\
\hline 250 & 728 & 0.35 & 1545 & 1533 \\
\hline 150 & 828 & 0.35 & 1626 & 1620 \\
\hline
\end{tabular}

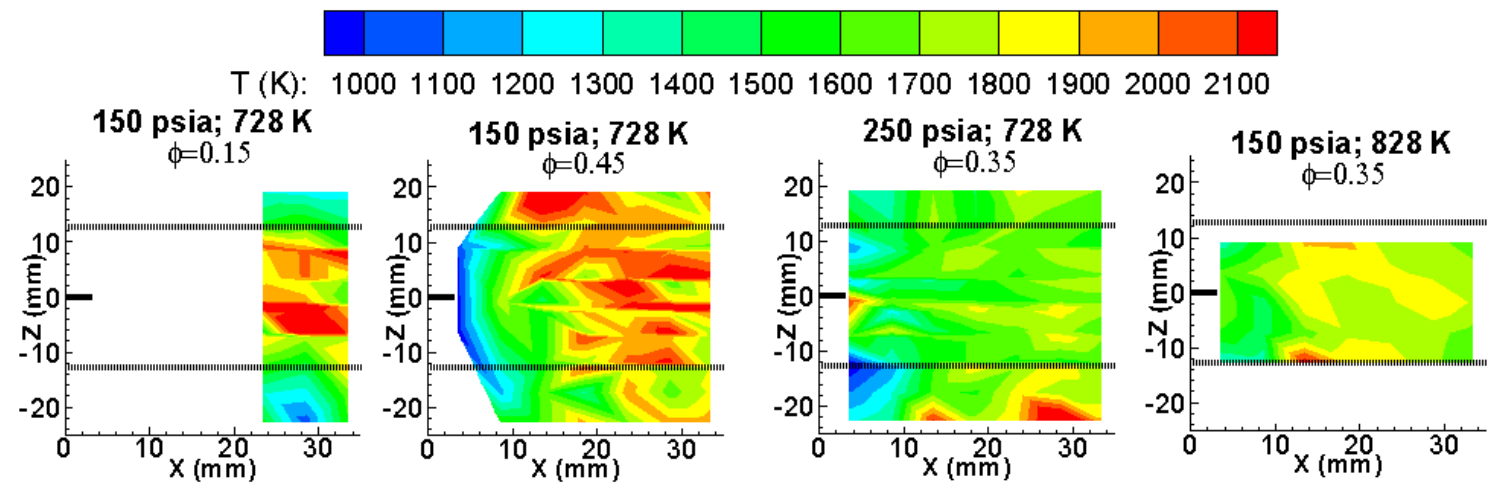

Figure 8.-Temperature y planes. Planes of temperature in Kelvin at $y=0$ at all four flame conditions. The small black lines at $z=0$ indicate the center of the center LDI element. The dotted lines at $y= \pm 12.7 \mathrm{~mm}$ indicate the location of the midpoint between LDI elements.

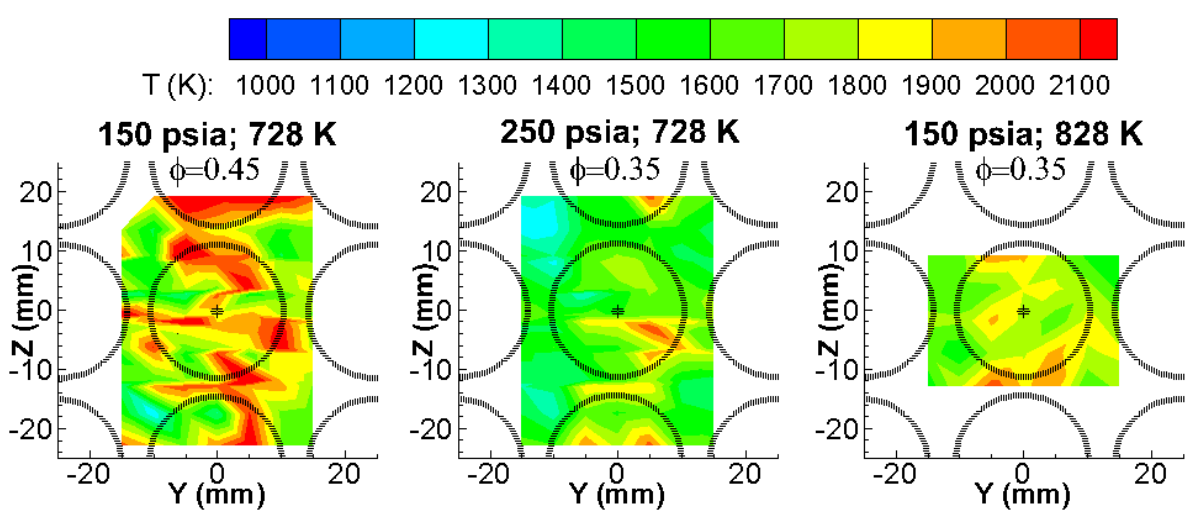

Figure 9.-Temperature $x$ planes. Planes of temperature in Kelvin at $x=18.5$ at three flame conditions. The small black crosshairs at $z=0$ indicate the center of the center LDI element. The dotted circles indicate the perimeter of the diffusers at the domes of the LDI elements. 
Figures 10 to 12 are the $\mathrm{z}$ planes at five $\mathrm{z}$ locations, $-13,-7.45,-1.9,3.7$, and $9.25 \mathrm{~mm}$. Figure 10 shows z planes for the $150 \mathrm{psi}, 728 \mathrm{~K}, \phi=0.15$ (center injector only) condition. The trends match those shown in Figure 8 for the same flame condition with the hottest region downstream of the center of the center injector at $\mathrm{z}=-1.9 \mathrm{~mm}$. Figure 11 are the $\mathrm{z}$ planes for $150 \mathrm{psia}, 728 \mathrm{~K}, \phi=0.45$ condition. This condition, as shown in Figures 8 and 9, has the largest region of temperatures above $2100 \mathrm{~K}$. Figure 12 shows the z planes for the $250 \mathrm{psia}, 828 \mathrm{~K}, \phi=0.35$ flame condition. Again this condition has the lowest temperatures of all the flame conditions matching the trends shown in Figures 8 and 9.
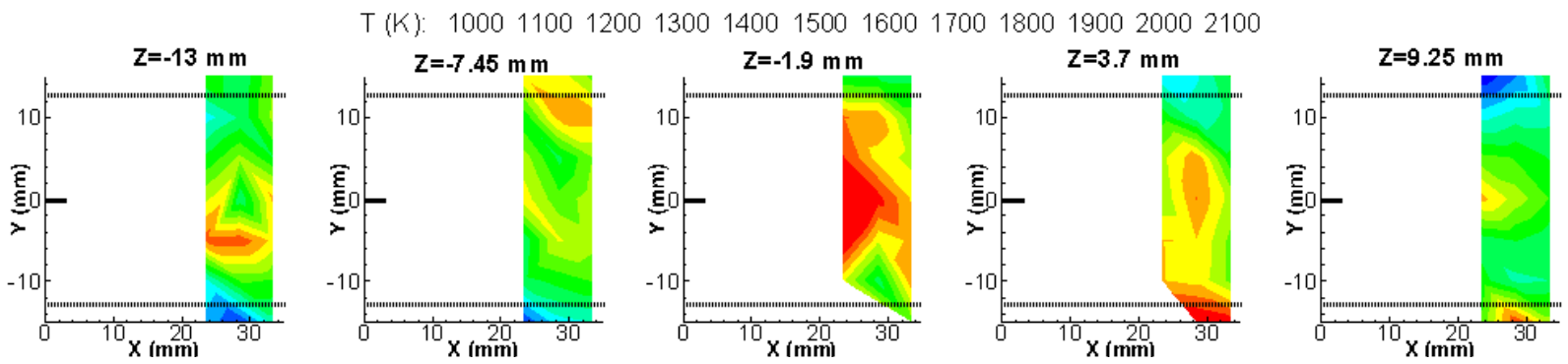

Figure 10.-Temperature z planes at 150 psia, $728 \mathrm{~K}, \phi=0.15$, center injector only. Five $z$ planes of temperature in Kelvin. The small black lines at $y=0$ indicate the center of the center LDI element. The dotted lines at $y= \pm 12.7 \mathrm{~mm}$ indicate the location of the midpoint between LDI elements.
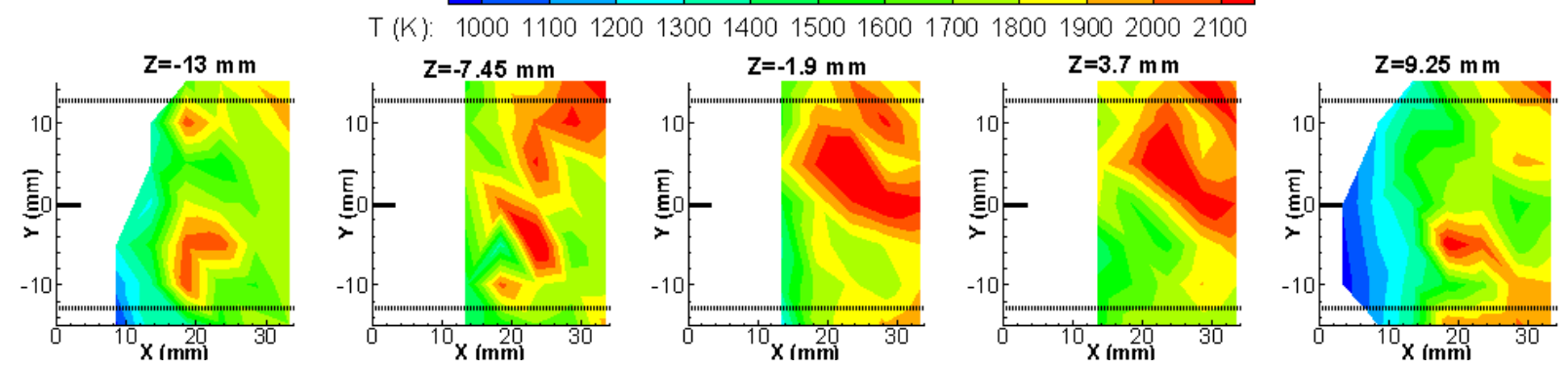

Figure 11.-Temperature z planes at 150 psia, $728 \mathrm{~K}, \phi=0.45$, all injectors. Five z planes of temperature in Kelvin. The small black lines at $y=0$ indicate the center of the center LDI element. The dotted lines at $y= \pm 12.7 \mathrm{~mm}$ indicate the location of the midpoint between LDI elements.
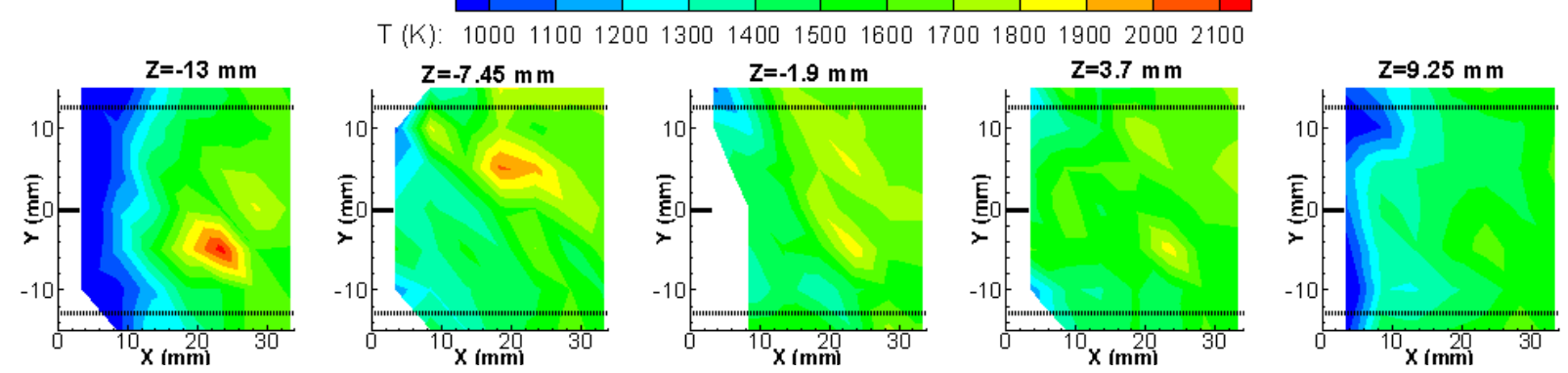

Figure 12.-Temperature z planes at 250 psia, $728 \mathrm{~K}, \phi=0.35$. Five $z$ planes of temperature in Kelvin. The small black lines at $y=0$ indicate the center of the center LDI element. The dotted lines at $y= \pm 12.7 \mathrm{~mm}$ indicate the location of the midpoint between LDI elements. 


\subsection{Species}

Species concentrations measured by SRS, at the operating conditions in Table 1, are shown in Figures 13 to 21 . All species are measured relative to nitrogen. The scaling of concentration in all the figures is matched.

Figures 13 to 15 show the relative species concentrations at planes $\mathrm{y}=0 \mathrm{~mm}$ and $\mathrm{x}=18.5 \mathrm{~mm}$ for conditions 250 psia, $728 \mathrm{~K}, \phi=0.35$ and 150 psia, $828 \mathrm{~K}, \phi=0.35$. Figure 13 shows the amount of oxygen concentration relative to nitrogen. As expected the lowest temperature flame condition measured in Figure 8 ( 250 psia, $728 \mathrm{~K}, \phi=0.35$ ) has higher levels of oxygen than the flame condition 150 psia, $828 \mathrm{~K}, \phi=0.35$. In Figure 14 are y and x-planes of carbon dioxide concentration relative to nitrogen. Figure 15 shows the amount of water concentration relative to nitrogen. Comparing Figures 13, 14, and 15 indicates turbulent combustion. There are isolated pockets of high concentration of all three measured species as well as pockets of low concentration. These variances in concentration are a combination of mixing and combustion effects that are not fully understood and are under investigation.
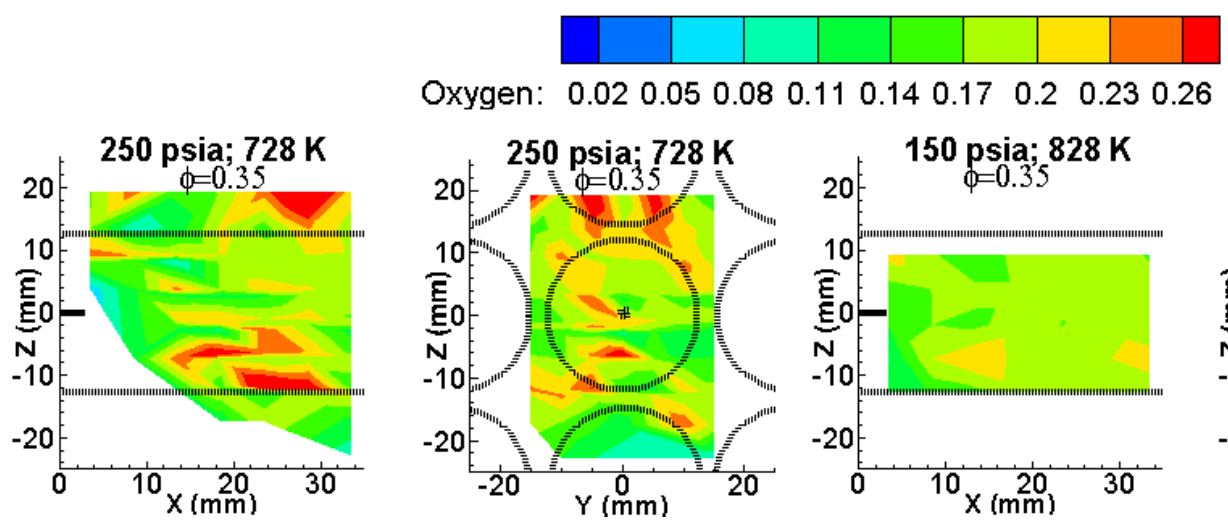

Oxygen: $0.020 .050 .08 \quad 0.110 .140 .17 \quad 0.2 \quad 0.23 \quad 0.26$
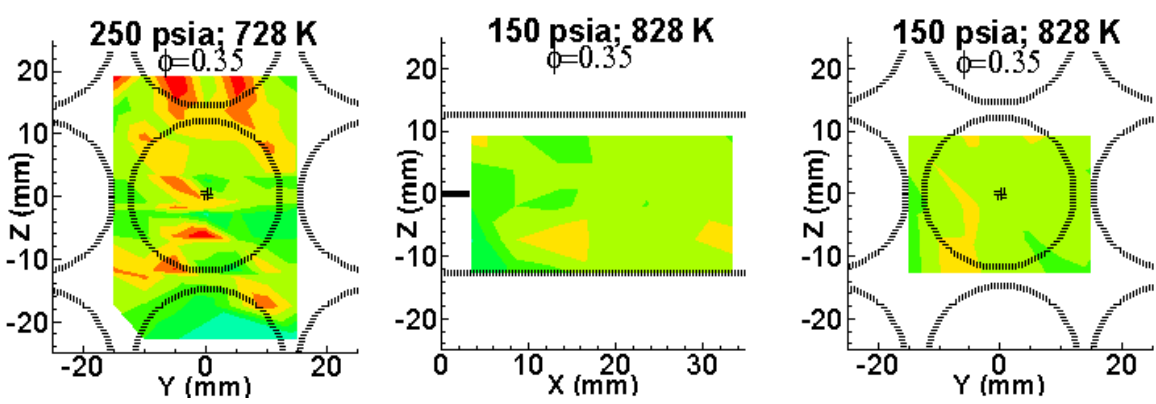

Figure 13.-Oxygen $y$ and $x$ planes. Planes of oxygen concentration relative to nitrogen at $y=0 \mathrm{~mm}$ and $x=18.5 \mathrm{~mm}$. The small black lines at $z=0$ indicate the center of the center LDI element. The dotted lines at $y= \pm 12.7 \mathrm{~mm}$ indicate the location of the midpoint between LDI elements. The small black crosshairs at $z=0$ indicate the center of the center LDI element. The dotted circles indicate the perimeter of the diffusers at the domes of the LDI elements.
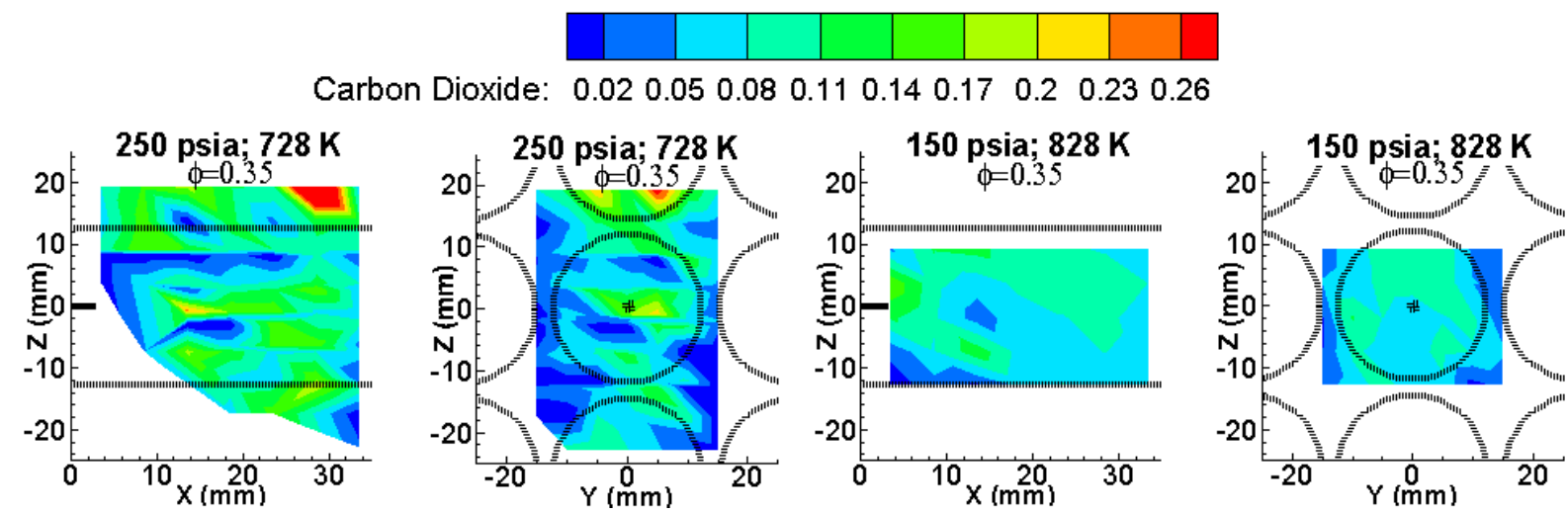

Figure 14.-Carbon Dioxide $y$ and $x$ planes. Planes of carbon dioxide concentration relative to nitrogen at $y=0 \mathrm{~mm}$ and $x=18.5 \mathrm{~mm}$. The small black lines at $z=0$ indicate the center of the center LDI element. The dotted lines at $y= \pm 12.7 \mathrm{~mm}$ indicate the location of the midpoint between LDI elements. The small black crosshairs at $z=0$ indicate the center of the center LDI element. The dotted circles indicate the perimeter of the diffusers at the domes of the LDI elements. 
Water: $\begin{array}{lllllllll}0.02 & 0.05 & 0.08 & 0.11 & 0.14 & 0.17 & 0.2 & 0.23 & 0.26\end{array}$
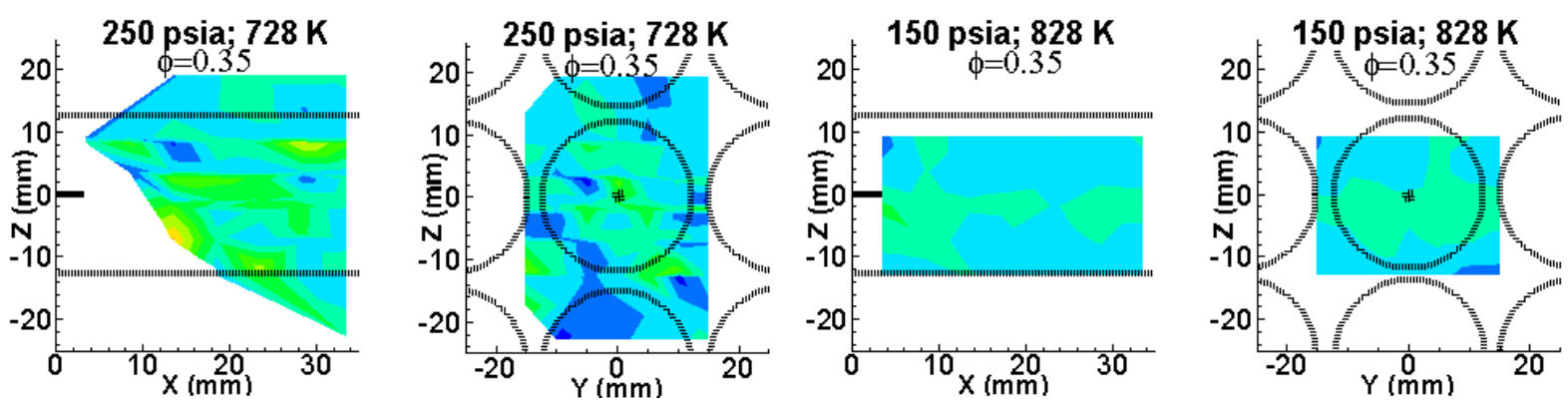

Figure 15.-Water $y$ and $x$ planes. Planes of water concentration relative to nitrogen at $y=0 \mathrm{~mm}$ and $x=18.5 \mathrm{~mm}$. The small black lines at $z=0$ indicate the center of the center LDI element. The dotted lines at $y= \pm 12.7 \mathrm{~mm}$ indicate the location of the midpoint between LDI elements. The small black crosshairs at $z=0$ indicate the center of the center LDI element. The dotted circles indicate the perimeter of the diffusers at the domes of the LDI elements.

\section{Oxygen: $\quad 0.020 .050 .08 \quad 0.11 \quad 0.14 \quad 0.17 \quad 0.2 \quad 0.23 \quad 0.26$}
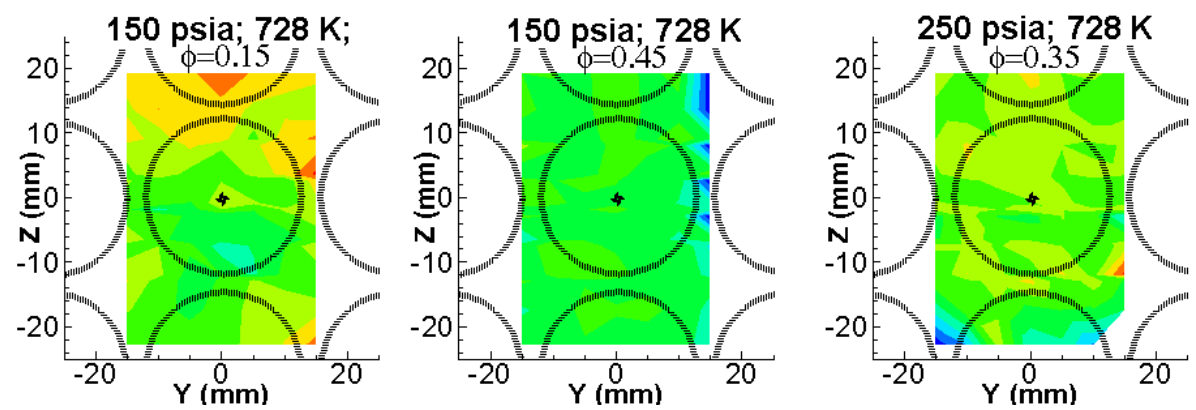

Figure 16.-Oxygen downstream $x$ planes. Planes of oxygen concentration relative to nitrogen at $x=33.5 \mathrm{~mm}$. The small black crosshairs at $z=0$ indicate the center of the center LDI element. The dotted circle indicates the location of the outside ring of the dome of the center LDI element.

Figures 16 to 18 show the conditions 150 psia; $728 \mathrm{~K} ; \phi=0.15,150$ psia; $728 \mathrm{~K} ; \phi=0.45$, and 250 psia; $728 \mathrm{~K} ; \phi=0.35$ at the plane $\mathrm{x}=33.5 \mathrm{~mm}$ for the relative concentrations of oxygen, water, and carbon dioxide, respectively. In Figure 16 it is interesting to note the high relative concentrations of oxygen near the edges of the measured plane for the center injector only condition in comparison to the all injectors condition with the same inlet temperature and pressure. The higher concentrations of oxygen in these regions indicate a non-combusting region. This is supported by the similarly located low temperature regions for this condition shown in Figure 8. In Figures 17 and 18 the carbon dioxide and water concentration is highest in the region of the center injector for the center injector only condition. These trends indicate the expected result of combustion only occurring near the center injector. Comparing the all injectors conditions at the pressures 150 and 250 psia the lower pressure condition has lower oxygen concentration and higher carbon dioxide and water concentrations.

Figures 19 to 21 show the $\mathrm{z}$ planes of the relative species concentration which has coordinates that match the temperature planes at the 250 psia, $728 \mathrm{~K}, \phi=0.35$ flame condition in Figure 12. In Figure 19, the relative oxygen concentration to nitrogen tends to decrease downstream which corresponds to low temperature regions in Figure 12. Comparing Figure 19 with Figures 20 and 21 the regions of low oxygen concentration correspond to regions of high carbon dioxide and water concentration indicating regions of competed combustion. 
Carbon Dioxide: $0.02 \quad 0.050 .08 \quad 0.110 .140 .17 \quad 0.20 .23 \quad 0.26$
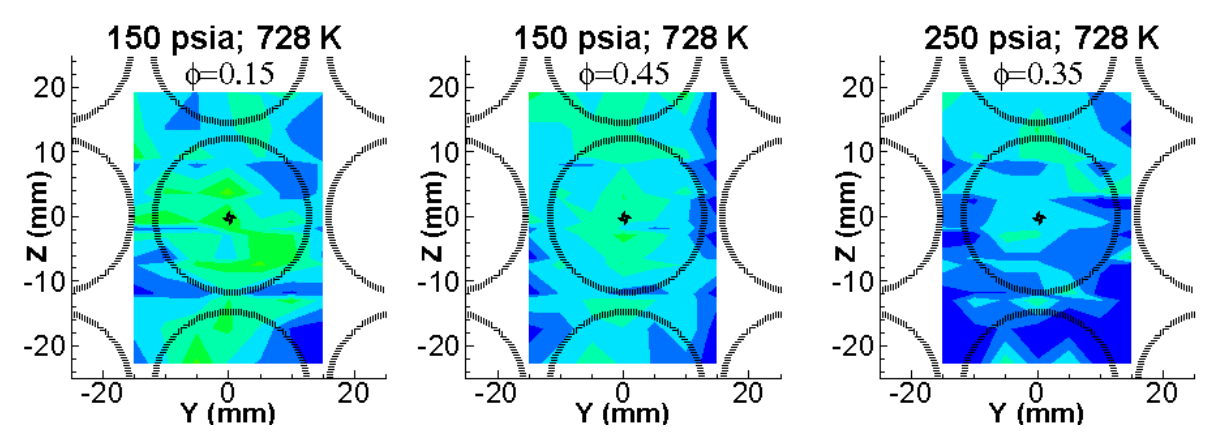

Figure 17.-Carbon dioxide downstream $x$ planes. Planes of carbon dioxide concentration relative to nitrogen at $x=33.5 \mathrm{~mm}$. The small black crosshairs at $z=0$ indicate the center of the center LDI element. The dotted circles indicate the perimeter of the diffusers at the domes of the LDI elements.

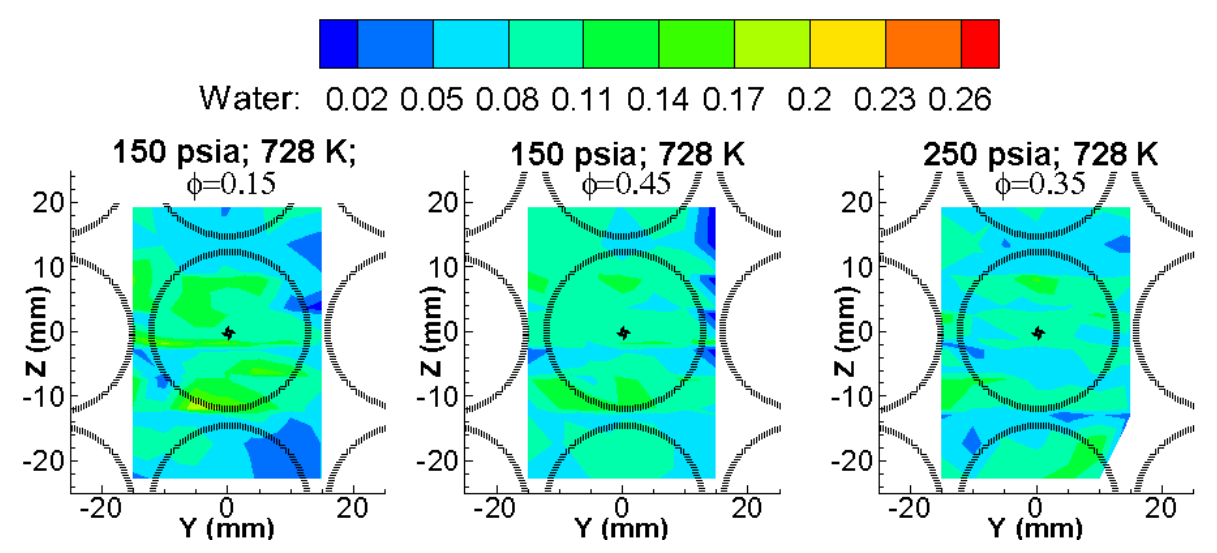

Figure 18. -Water downstream $x$ planes. Planes of water concentration relative to nitrogen at $x=33.5 \mathrm{~mm}$. The small black crosshairs at $z=0$ indicate the center of the center LDI element. The dotted circles indicate the perimeter of the diffusers at the domes of the LDI elements.
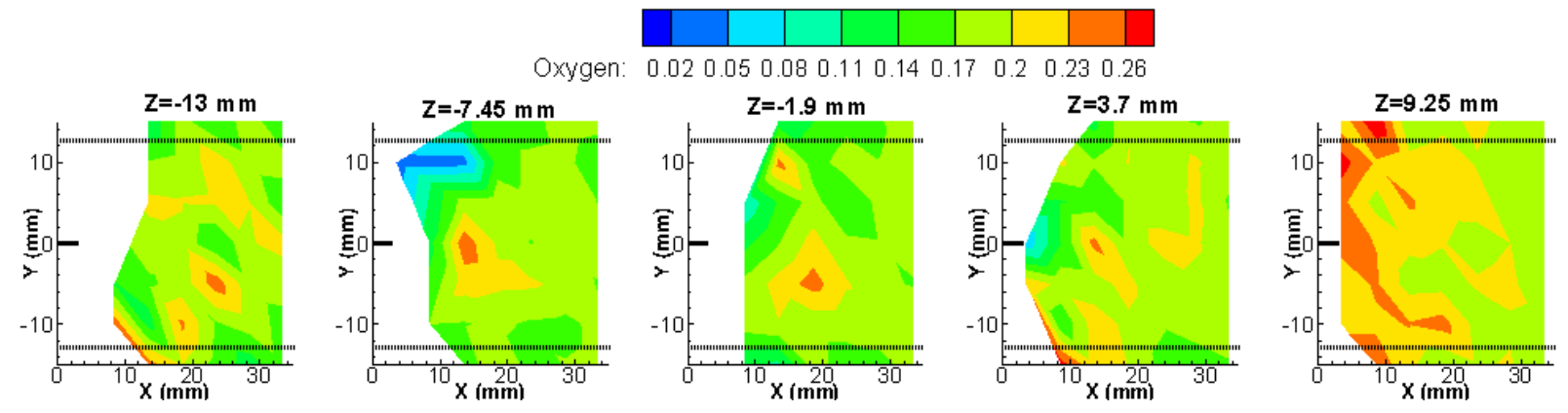

Figure 19.-Oxygen z planes at flame condition: 250 psia, $728 \mathrm{~K}, \phi=0.35$. Five $z$ planes of oxygen concentration relative to nitrogen. The small black lines at $y=0$ indicate the center of the center LDI element. The dotted lines at $y= \pm 12.7 \mathrm{~mm}$ indicate the location of the midpoint between LDI elements. 

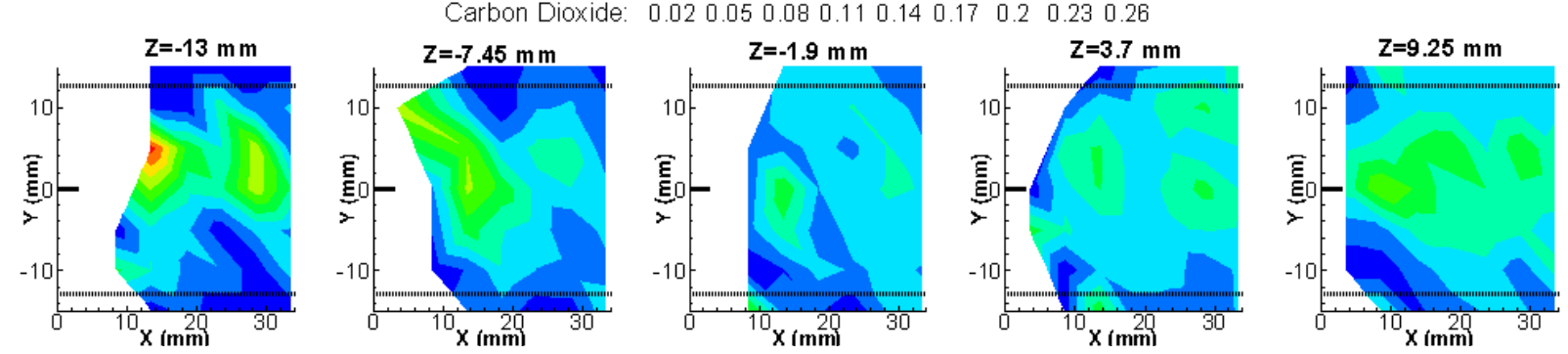

Figure 20.-Carbon dioxide z planes at flame condition: 250 psia, $728 \mathrm{~K}, \phi=0.35$. Five z planes of carbon dioxide concentration relative to nitrogen. The small black lines at $y=0$ indicate the center of the center LDI element. The dotted lines at $y= \pm 12.7 \mathrm{~mm}$ indicate the location of the midpoint between LDI elements.
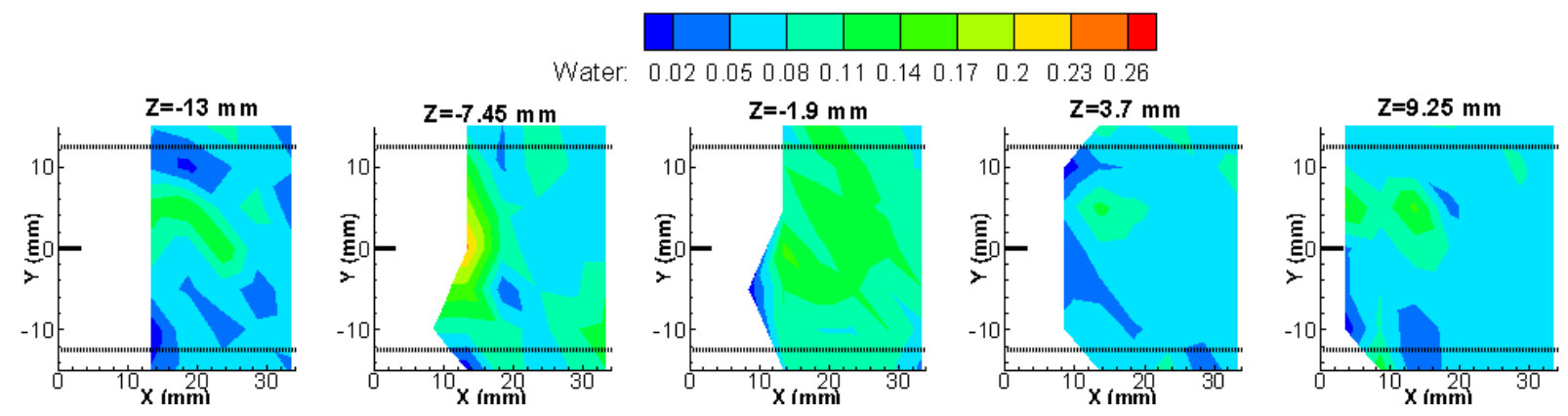

Figure 21.-Water z planes at flame condition: 250 psia, $728 \mathrm{~K}, \phi=0.35$. Five $z$ planes of water concentration relative to nitrogen. The small black lines at $y=0$ indicate the center of the center LDI element. The dotted lines at $y= \pm 12.7 \mathrm{~mm}$ indicate the location of the midpoint between LDI elements.

\subsection{Conclusion}

SRS measurements of a 9-point LDI were collected at four flame conditions. These temperature and relative species concentrations will contribute to the 9-point LDI data base and increase the understanding of its combustion flow. The temperatures matched the trends estimated by the flame temperature except for the center injector only flame condition. Because the Raman measurement locations were targeted near the center injector, the overall equivalence ratio used to estimate the flame temperature estimated a lower average temperature than was measured downstream of the center injector. The comparison of the estimated flame temperature to the measured spatially averaged temperature may be improved if the full region of the flow was measured or the local equivalence ratio was used to calculate the estimated flame temperature.

While the coefficient calibration method described in this work showed an increase in accuracy, the method can be improved. In this work these calibration measurements were only collected at the axes. In future measurements more spatial variance in the coefficient can be preserved by measuring at all locations. Even if this is implemented in future measurements this procedure may not eliminate all coefficient variance. For example, while the preservation of the spatial variance improves the coefficients for the calibration measurements, there may be a change in the coefficients when combustion is occurring. As the temperature increases, the shape of the combustion chamber changes, thus changing the properties of the laser reflections. The spatial coefficient calibration was only done for deriving temperature because in situ measurements of the species were not possible. A way to perform in situ species measurement of gas mixtures of known concentrations is being investigated. 
Improvements to the quality of the measurements can be made. While the current measurements show general trends of the combustion flow field, smaller combustion structures could be measured if the spatial resolution was increased. The measurements presented in this work are time averaged. The understanding of the combustion flow could be increased by time resolving the measurements. To achieve this single shot data should be collected. The single shot spectra collected during this experiment had insufficient signal-to-noise. Therefore to allow time resolution the signal-to-noise of the spectra must be increased. Spectral overlap of oxygen and carbon dioxide added an unknown amount of error to the oxygen measurements. A method to eliminate this error source by using the carbon dioxide measurements obtained from the $2 \Sigma v_{2}$ peak to estimate the interaction between peaks is under consideration. Finally, to allow CFD modelers to compare their models with these measurements, the accuracy and precision of the species calibration should be measured. This could be accomplished by measuring gas mixtures with varied but known concentrations.

\section{References}

1. Tacina, R., Lee, P., Wey, C., “A Lean-Direct-Injection Combustor Using a 9 Point Swirl-Venturi Fuel Injector,” ISABE-2002-1106.

2. Hicks, Y.R., Heath, C.M, Anderson, R.C., Tacina, K.M., "Investigations of a Combustor Using a 9-Point”.

3. "Swirl-Venturi Fuel Injector: Recent Experimental Results," 20th International Symposium on Air Breathing Engines (ISABE 2011), Göteborg, Sweden, September 12-16, 2011, ISABE-2011-1106.

4. Hicks, Y.R., Anderson, R.C., Locke, R.J., "Optical Measurements in a Combustor Using a 9-Point Swirl-Venturi Fuel Injector,” ISABE 2007-1280.

5. Hicks, Y.R., Tacina, K.M., "Comparing a Fischer-Tropsch Alternate Fuel to JP-8 and their 50-50 Blend: Flow and Flame Visualization Results,” Spring Technical Meeting of the Central States Section of the Combustion Institute, April 22-24, 2012.

6. Gu, Y., Rothe, E.W., Reck, G.P., Anderson, R.C., Hicks, Y.R., Zaller, M., Nguyen, Q., Locke, R.J., “1-D, UV-Raman Imaging from a High Pressure, Jet-A Fueled, Gas Turbine Combustor," $38^{\text {th }}$ Aerospace Sciences Meeting and Exhibit, Reno, NV 10-13 January 2000, AIAA 2000-0773.

7. Thariyan, M.P., Bhuiyan, A.H., Meyer, S.E., Naik, S.V., Gore, J.P., Lucht, R.P., "Dual-pump coherent anti-Stokes Raman scattering system for temperature and species measurements in an optically accessible high-pressure gas turbine combustor facility,” Meas. Sci. Technol., Vol. 22, pp. 1-12, December 2011.

8. Eckbreth, A.C., Laser Diagnostics for Combustion Temperature and Species, 2nd Ed., Gordon and Breach Pub., 1996.

9. Sweeny, M.S., Hochgreb, S., Barlow, R.S., "The structure of premixed and stratified low turbulence flames,” Combustion and Flame, Vol. 158, pp. 935-958., May, 2011. 


\begin{tabular}{|c|c|c|}
\hline \multicolumn{2}{|c|}{ REPORT DOCUMENTATION PAGE } & $\begin{array}{l}\text { Form Approved } \\
\text { OMB No. 0704-0188 }\end{array}$ \\
\hline \multicolumn{3}{|c|}{$\begin{array}{l}\text { The public reporting burden for this collection of information is estimated to average } 1 \text { hour per response, including the time for reviewing instructions, searching existing data sources, gathering and maintaining the } \\
\text { data needed, and completing and reviewing the collection of information. Send comments regarding this burden estimate or any other aspect of this collection of information, including suggestions for reducing this } \\
\text { burden, to Department of Defense, Washington Headquarters Services, Directorate for Information Operations and Reports ( } 0704-01808 \text {, } 1215 \text { Jefferson Davis Highway, Suite } 1224 \text {, Allington, VA } 222202-4302 \text {. } \\
\text { Respondents should be aware that notwithstanding any other provision of law, no person shall be subject to any penalty for failing to comply with a collection of information if it does not display a currently valid OMB } \\
\text { control number. } \\
\text { PLEASE DO NOT RETURN YOUR FORM TO THE ABOVE ADDRESS. }\end{array}$} \\
\hline $\begin{array}{l}\text { 1. REPORT DATE (DD-MM-YYYY) } \\
01-01-2013\end{array}$ & $\begin{array}{l}\text { 2. REPORT TYPE } \\
\text { Technical Memorandum }\end{array}$ & 3. DATES COVERED (From - To) \\
\hline \multirow{3}{*}{\multicolumn{2}{|c|}{$\begin{array}{l}\text { 4. TITLE AND SUBTITLE } \\
\text { Temperature and Species Measurements of Combustion Produced by a 9-Point Lean Direct } \\
\text { Injector }\end{array}$}} & 5a. CONTRACT NUMBER \\
\hline & & 5b. GRANT NUMBER \\
\hline & & 5c. PROGRAM ELEMENT NUMBER \\
\hline \multirow{3}{*}{\multicolumn{2}{|c|}{$\begin{array}{l}\text { 6. AUTHOR(S) } \\
\text { Tedder, Sarah, A.; Hicks, Yolanda, R.; Locke, Randy, J. }\end{array}$}} & 5d. PROJECT NUMBER \\
\hline & & 5e. TASK NUMBER \\
\hline & & $\begin{array}{l}\text { 5f. WORK UNIT NUMBER } \\
\text { WBS 794072.02.03.05.02 }\end{array}$ \\
\hline \multicolumn{2}{|c|}{$\begin{array}{l}\text { 7. PERFORMING ORGANIZATION NAME(S) AND ADDRESS(ES) } \\
\text { National Aeronautics and Space Administration } \\
\text { John H. Glenn Research Center at Lewis Field } \\
\text { Cleveland, Ohio 44135-3191 }\end{array}$} & $\begin{array}{l}\text { 8. PERFORMING ORGANIZATION } \\
\text { REPORT NUMBER } \\
\text { E-18581 }\end{array}$ \\
\hline \multirow{2}{*}{\multicolumn{2}{|c|}{$\begin{array}{l}\text { 9. SPONSORING/MONITORING AGENCY NAME(S) AND ADDRESS(ES) } \\
\text { National Aeronautics and Space Administration } \\
\text { Washington, DC 20546-0001 }\end{array}$}} & $\begin{array}{l}\text { 10. SPONSORING/MONITOR'S } \\
\text { ACRONYM(S) } \\
\text { NASA }\end{array}$ \\
\hline & & $\begin{array}{l}\text { 11. SPONSORING/MONITORING } \\
\text { REPORT NUMBER } \\
\text { NASA/TM-2013-217830 }\end{array}$ \\
\hline \multicolumn{3}{|c|}{$\begin{array}{l}\text { 12. DISTRIBUTION/AVAILABILITY STATEMENT } \\
\text { Unclassified-Unlimited } \\
\text { Subject Categories: } 35 \text { and } 07 \\
\text { Available electronically at http://Www.sti.nasa.gov } \\
\text { This publication is available from the NASA Center for AeroSpace Information, 443-757-5802 }\end{array}$} \\
\hline
\end{tabular}

\section{SUPPLEMENTARY NOTES}

\section{ABSTRACT}

This paper presents measurements of temperature and relative species concentrations in the combustion flowfield of a 9-point swirl venturi lean direct injector fueled with JP-8. The temperature and relative species concentrations of the flame produced by the injector were measured using spontaneous Raman scattering (SRS). Results of measurements taken at four flame conditions are presented. The species concentrations reported are measured relative to nitrogen and include oxygen, carbon dioxide, and water.

\section{SUBJECT TERMS}

Injection; Raman spectroscopy

\begin{tabular}{|c|c|c|c|c|c|}
\hline \multicolumn{3}{|c|}{ 16. SECURITY CLASSIFICATION OF: } & \multirow{2}{*}{$\begin{array}{l}\text { 17. LIMITATION OF } \\
\text { ABSTRACT } \\
\text { UU }\end{array}$} & \multirow{2}{*}{$\begin{array}{l}\text { 18. NUMBER } \\
\text { OF } \\
\text { PAGES } \\
22\end{array}$} & \multirow{2}{*}{$\begin{array}{l}\text { 19a. NAME OF RESPONSIBLE PERSON } \\
\text { STI Help Desk (email:help@sti.nasa.gov) } \\
\text { 19b. TELEPHONE NUMBER (include area code) } \\
\text { 443-757-5802 }\end{array}$} \\
\hline $\begin{array}{l}\text { a. REPORT } \\
U\end{array}$ & $\begin{array}{l}\text { b. ABSTRACT } \\
\text { U }\end{array}$ & $\begin{array}{l}\text { c. THIS } \\
\text { PAGE } \\
\text { U }\end{array}$ & & & \\
\hline
\end{tabular}



